\title{
THE SCIENTIFIC ADVANCEMENT AND PROMOTION OF THE JOURNAL "COMPUTER OPTICS" IN 2014-2015
}

\author{
D.V. Kudryashov \\ Samara National Research University, Samara, Russia
}

\begin{abstract}
The paper describes the work done in terms of raising the profile of the scientific journal "Computer Optics" in the international scientific community. Marked changes in the work: change the frequency of publication and indexation of new scientific databases. It is also observed changes in the editorial staff and the design of scientific articles. The perspectives of the journal entry to the international reference-Bibliography-graphically and scientometric database.
\end{abstract}

Keywords: scientific journal, editors, publisher, publication activity.

Citation: Kudryashov DV. The scientific advancement and promotion of the journal "Computer Optics" in 2014-2015. CEUR Workshop Proceedings, 2016; 1638: 185-193. DOI: 10.18287/1613-0073-2016-1638-185-193

\section{Introduction}

In the middle of 2014 the chief editor of the scientific journal "Computer Optics", Corresponding Member of the Russian Academy of Sciences Soifer V.A., in his article «Quo vadis» [1] put in front of authors and editorial staff the new objectives which already started to be fulfilled last year. The 2015th became a transitional period for the journal both in terms of changing the periodicity of publication and in the emergence of new forms of work organization. The challenges facing the founders of the journal, Samara State Aerospace University (SSAU) and Image Processing Systems Institute (IPSI) of Russian Academy of Sciences (RAS), dictate the search for new forms of development of the "Computer optics" journal and its promotion in the international scientific and information environment.

\section{Changes}

Over the 28 years of existence of "Computer optics" journal (the first two issues were published and prepared by the International Centre for Scientific and Technical Information (ICSTI) in the framework of information support for a comprehensive program of scientific and technical progress of the CMEA member countries [2] in 
1987) 39 volumes were released. Until 2007 the edition, which was at that time an international compilation, was published irregularly, from one to three issues per year. Since 2007 the journal starts to come out in 4 issues per year. 2015 became a transitional one for the editorial board: there were released five issues in Russian and one special edition in English, "Computer Optics" (it included translated versions of the articles published in "Computer Optics" for the last two years).

The journal "is published with the financial support of the Government of Samara region" [2], but the bulk of the costs for production of publications are taken by IPSI RAS and SSAU.

In the work on the journal are involved three RAS academicians (Yu.I. Zhuravlev, V.Y. Panchenko, I.A. Shcherbakov), three corresponding member of Russian Academy of Sciences (S.Y. Zheltov, B.V. Kryzhanovsky, V.A. Soifer), six doctors of sciences (N.L. Kazanskiy, V.V. Kotlyar, V.S. Paveliev, V.V. Sergeev, S.N. Khonina and V.M. Chernov), as well as scientists from Germany (professor Richard Kowarschik), India (professor Kehar Singh), China (academician Jin Guofan) and Finland (professor Jari Turunen).

The average volume of one issue is 60 printed pages, circulation is over 300 copies (depending on subscription). Last year all in all 106 scientific articles were published in the journal in three main areas: diffractive optics, optical technologies; image processing, pattern recognition, analysis of hyperspectral data. The section "Analysis of hyperspectral data" [3-7] appeared in the journal in 2014 and became one of the most cited in other scientific publications. During 2015 there appeared new sections, such as: numerical methods and data analysis [8-10]; optoinformational technologies $[11,12]$; Earth remote sensing technologies $[13,14]$.

In 2015 in the journal, according to international standards, information has been added on citation: every article contains data on how to refer to it, and from the fourth number of volume 39 DOI (Digital Object Identifier) is assigned to each publication, a unique digital object identifier. Also the view of the English list of references has changed: references design is not given by the GOST, but in accordance with the requirements of the international citation database "SCOPUS".

Amendments continued also in 2016. As a result of participation of the journal editorial board members in the XV seminar-conference 5-100 project in Yekaterinburg [15] it was recommended that "Computer Optics" authors broadened the scope of annotation in the English part, as well as published the acknowledgements in English.

Adherence to international standards contribute positively to edition of the scientific journal from the point of view of a member of the Presidium of European Association of Scientific Editors (EASE), the main editor of "European Science Editing" journal A.J. Gasparyan [16]. According to these requirements, in the part of design in each issue "Computer Optics" represents the content and information about the journal in English along with the Russian. The names of cities and countries have been added to the affiliation.

Moreover, taking into consideration the recommendations of Thomson Reuters specialists on the results of scientific and practical seminar "Interdisciplinary science communications and editing. Tasks of ethical preparation and publication of science research results in journals indexed in global databases of Web of Science and Scopus citation", which took place in Samara State Aerospace University in spring of 2015, 
"Computer Optics" has significantly increased the number of foreign sources of literature in the References. This dramatically increases the chances of an article to be well cited in other journals, and thus increases the citation of "Computer Optics". Almost in every article published in the journal, you can see the sources of foreign literature.

\section{Authors}

Since the early 90 -ies foreign scientists are actively published in the compilation such as Neil Gallagher and Donald Sweney (United States), I.D. Nikolov (Bulgaria), R. Thaler, L. Dimitrov, E. Wenger (Austria) and others [17]. 2015 was not an exception: O'Faolain Liam (United Kingdom) [18], Choudhry Komal Kumari (India) [19], Thanh Dang Ngoc Hoang (Vietnam) [20] published their articles in "Computer Optics".

According to the electronic library eLIBRARY.RU data, in recent years the most cited were the members of the journal editorial board: N.L. Kazanskiy, S.N. Khonina, V.V. Kotlyar (Table 1). And the most published author is professor Kotlyar.

Table 1. Distribution of citations of the main authors of "Computer Optics" journal

\begin{tabular}{rlr}
\hline № & Author & Citings \\
1 & Kazanskiy N.L. & 873 \\
2 & Soifer V.A. & 815 \\
3 & Khonina S.N. & 616 \\
4 & Kotlyar V.V. & 497 \\
5 & Doskolovich L.L. & 317 \\
6 & Skidanov R.V. & 276 \\
7 & Kharitonov S.I. & 250 \\
8 & Volkov A.V. & 207 \\
9 & Murzin S.P. & 188 \\
\hline
\end{tabular}

The "balance of forces" at the end of 2014-2015 did not change: still the most cited authors of "Computer Optics" are N.L. Kazanskiy, S.N. Khonina, as well as the leading research employee of the laboratory of diffractive optics of IPSI RAS Kharitonov S.I. By the number of publications in the journal S.N. Khonina and V.V. Kotlyar became leaders (Table 2).

Table 2. The largest number of articles published by the authors in "Computer Optics" journal in 2014-2015

\begin{tabular}{llc}
\hline oo & Author & $\begin{array}{c}\text { Number of publications } \\
(2014 / 2015)\end{array}$ \\
1 & Khonina S.N. & $16 / 10$ \\
2 & Kotlyar V.V. & $15 / 14$ \\
3 & Kazanskiy N.L & $9 / 6$ \\
4 & Myasnikov V.V. & $9 / 1$ \\
5 & Doskolovich L.L & $8 / 8$ \\
6 & Kovalev A.A. & $8 / 7$ \\
7 & Skidanov R.V. & $8 / 6$ \\
\hline
\end{tabular}

For the last two years the most cited articles became publications of Kemerovo scientists A.A. Zvekov, A.V. Kalensky, A.P. Nikitin and B.P. Aduev [21] and the 
Samara scientists N.L. Kazansky, S.N. Khonina, R.V. Skidanov, A.A. Morozov, S.I. Kharitonov, S.G. Volotovsky, V.A. Fursov [22, 3, 23].

The data in Table 2 indicate a slight decline in the last two years of publication activity of authors affiliated with the founders of "Computer Optics" (IPSI RAS and SSAU), on the background of growth of the journal periodicity. This, in turn, is a consequence of the gradual implementation of the tasks set by chief editor V.A. Soifer in late 2014: "... It is necessary to continue work to improve the quality of publications, to significantly expand the share of the authors, not affiliated with the journal's founders. At the same time the editorial board does not plan drastic change or expanding the list of main scientific directions of the journal "[1]. The proof of these words is the fact that the number of articles from the "external" authors increases yearly (Figure 1).

\section{Promotion}

Since 17 October, 2001 the journal "Computer Optics" is included in the list of peerreviewed scientific journals recommended by the Higher Attestation Commission (HAC) of the Russian Ministry of science and education for publication of research results, reflecting the main content of master's and doctoral theses. In 2015 it was announced about the formation of a new List of scientific publications, certified by HAC (until November 30, 2015 the List acted in the version of 2010). At the beginning of December 2015 HAC sent an official confirmation that "Computer Optics" journal is included in the new list of peer-reviewed scientific publications, where basic scientific results should be published of dissertations for the degree of candidate of science, for the degree of Doctor of Science. New list of HAC came into force on 1 December.

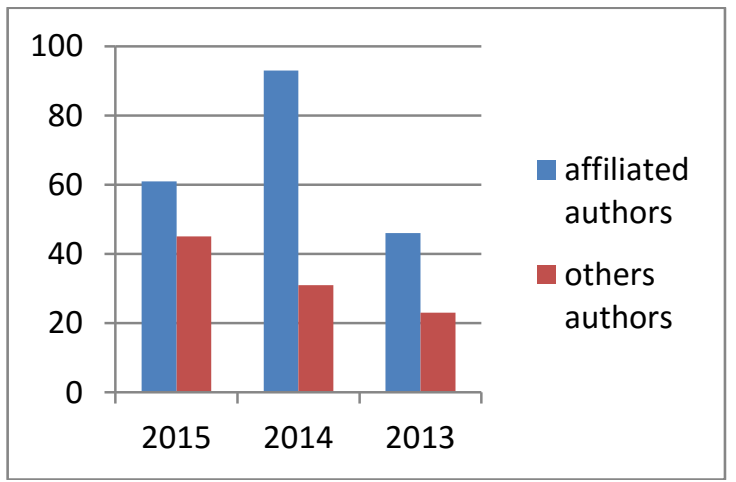

Fig. 1. The ratio of the number of articles from the "own" (affiliated to the journal) and from "external" authors for 2013-2015.

To a large extent "Computer Optics" could confirm its high status of scientific publication due to the fact that the journal articles are indexed in prestigious international databases. Since 2012, the journal is abstracted and indexed in international databases of scientific citing "SCOPUS" and "Compendex", which was a great achievement for a regional journal that does not have full text of the English 
version. During 2015 the archive issues of "Computer Optics" were added to SCOPUS database, since 2009 work is underway to add issues since 2005 to the database. For this pdf-files of archived issues were reformatted by forces of the editorial board to include English name and annotation, while retaining the old numbering of pages.

Since SCOPUS is constantly "brushing" scientific publications, we must always strictly observe the requirements of international standards. One of the conditions for exclusion from the SCOPUS can be a sharp rise (two to three times) of the journal publications, while maintaining periodicity. 2014 became a record one for "Computer Optics" by the number of articles (124 publications): compared with 2013 year an increase was 1.8 times. To protect ourselves from suspicion by the SCOPUS experts, since 2015, along with information about the date of getting the text, each article was provided with the information on the date of the end of the review of papers and the date of acceptance for publication. This proves that, despite the increase in the number of publications, the review process is carried out in good faith.

At the end of 2015 it became known that "Computer Optics" entered the scientometric base of Russian journal in Russian Science Citation Index (RSCI) on the Web of Science of Thomson Reuters company platform. Currently on RSCI there is available information on 500 articles from "Computer Optics"; the base continues filling. Accommodation in RSCI will improve the quality of the journal by bringing it closer to international standards, and will accelerate the bibliometric indicators in the Web of Science and integrated indicators of Russia in general by increasing the visibility and citation of the journal in the world.

The next step, according to the chief editor V.A. Soifer, should be "the journal entry in the Web of Sciences Core Collection. To do this, we need to continue working to improve the quality of publications "[1].

Electronic version of the articles from "Computer Optics" is placed in the public domain on the website http://www.computeroptics.smr.ru/. In spring 2016 a new edition website began working on ElPub http://www.computeroptics.ru publishers platform. Full versions of articles with annotations, affiliation, and keywords are also placed on the website of the scientific electronic library eLIBRARY.RU. This Internet resource estimates that the journal takes place in the first hundred (from 2500) in the ranking of citations of Russian scientific publications.

As part of the promotion strategy of the journal in 2015 the publisher of "Computer Optics", IPSI RAS, signed an agreement with Russian scientific electronic "KiberLeninka" library, which shows the full versions of articles of all journal issues for 2015. Accommodation in this electronic library on the open access model (Open Access), provides free online access to scientific publications in electronic form. Scientific texts represented in the library can be found as with the help of popular search systems, as well as through a system of full-text scientific research with support of Russian morphology on the library website. Library users are given the opportunity to read scientific works with the tablet screens, mobile phones, and other advanced mobile devices. Articles placed in the "KiberLeninka" are automatically exported into open international repositories of scientific information Google Scholar, OCLC WorldCat, ROAR, BASE, OpenAIRE, RePEc, Socionet, and others by the protocol OAI-PMH. 
Also since 2015 the journal publishes full-text issues for free access in the databases of Internet resource Open Academic Journals Index (OAJI) (the founder is the international network "Center of basic and applied research", Russia) and on the website of all-Russian mathematical portal MathNet , an innovative project of the RAS Mathematical Institute named after V.A. Steklov.

\section{English-language edition of the Computer Optics}

Since the release of the first issue of "Computer Optics" the publishing house "Pergamon Press" expressed an active interest in publication of the journal in English. This possibility was realized in 1989-1990, when two volumes (Vol 1, N 1, 1989; Vol $2, \mathrm{~N} \& \mathrm{~N} 12,1990$ ) were published with proliferation all over the world (at the front cover of the journal it was noted: Oxford - New York - Beijing - Frankfurt - Sao Paulo - Sydney - Tokyo - Toronto). The first volume was made up of the issue of the first compilation, and the second volume was based on the issues three and four [17]. In the scientific electronic library eLIBRARY.RU these English-language editions only became available in 2015, and the articles themselves were linked to existing profiles of the authors.

After 25 years the editorial board decided to resume production of "Computer Optics" in English at the expense of own means and resources. At the end of 2015 there was the release of a special English-language edition of "Computer Optics" (Figure 2), which included 22 articles published in the Russian version of the journal over the past two years. "Selected papers" became the first attempt of the journal edition for the foreign scientific community. For this aim the editorial board of the publishing department was expanded, and specially for "Computer Optics" has been developed a new design layout, corresponding to modern global trends in scientific periodicals.
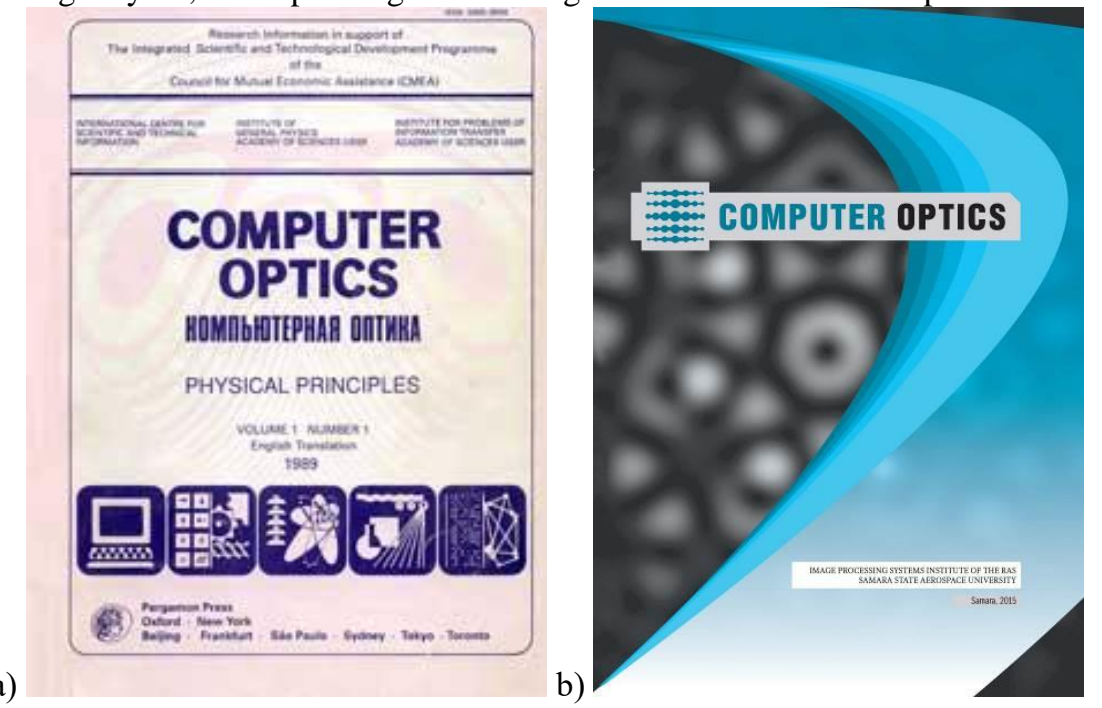

Fig. 2. The covers of the English language issues of "Computer Optics": a) version of 1989; b) special edition of 2015 . 
With the aim of corresponding to the level and quality of the English language publications, to meet international standards, a professional interpreter specializing in working with technical texts was involved for translation of the texts.

Special edition of "Computer Optics" was formed from the selected materials: the authors wishing to publish their articles in English provided their original of publication in Russian. One of the conditions was that the article had not been previously published in the same form in English.

"Computer Optics" publication was realized within the framework of the Program for increasing the competitiveness of SSAU among the world's leading research and education centers for 2013-2020. The editors hope that this goal at the end of 2015 was achieved. Besides, the English-language edition of the journal, which published the latest scientific achievements of the Samara region and other regions of Russia, will allow English-speaking scientists to get acquainted not only with the publication, but also with the scientific advances in the country.

\section{Prospects}

As the Dean of the Faculty of Informatics SSAU E.I. Kolomiets noted in his article [17], "a timely response to new directions of development of science and adherence to actual modern trends allows editorial board of "Computer Optics" to actively develop the journal and to improve its credibility and recognition in the scientific community." To achieve this goal, new tasks were set, before the editorial board and publishing authors stated in the article of V.A. Soifer «Quo vadis» [1]. According to these tasks, the editorial board of the journal "Computer Optics" in 2016 plans to increase periodicity to six issues a year, five of which will be in Russian and one - the original - in English. Also another special edition in English is planned with articles published in the Russian version of "Computer Optics" in 2015.

Work will be continued to attract new articles of high scientific level, to expand the circle of authors, thus ensuring a real opportunity for quick (within one quarter) and open (free access to the full text of the article) publication.

Due to the plans for the near future: extension of the reviewers institute because of increase in periodicity, there will be strict observance of the review terms. As V.A. Soifer noted, within a week of receipt of the article the editorial board should get two or three scientists consent to its review. "The review time is two weeks, after which the reviewers must provide the responses to the editorial board. Their editorial board together with the opinion of their responsible representative for this trend within a week should send the work to the author. Thus, the authors will receive a reasoned answer from the editorial board within 4 weeks ". [1] At the beginning of 2016 the editorial staff has formed an extended list of potential reviewers, some of which have already been brought to work on the first and second numbers of the 40th volume.

The filling of Russian and international databases and digital libraries with archival releases of "Computer Optics" will continue, thereby ensuring the most complete access to full versions of articles of the journal.

On the background of the global trend to reduce costs to produce scientific publications the editorial board of "Computer Optics" plans to attract sponsors for edition of the journal, as well as to participate in competitions for state and federal 
grants for production of the journal. In 2015 both Russian and English versions of "Computer Optics" received the gubernia grants in the field of science and technology for publication of the journal. A similar application was submitted and approved by the expert committee also on the results of the first half of 2016

On the pages of "Computer Optics" there must appear, especially in English-language releases, advertisements and announcements of upcoming scientific conferences and seminars on the edition profile. "The prospect of the journal themes, integrating achievements of computer optics, nanophotonics diffraction and digital image processing, seems extremely important not only for domestic but also for all the world of science, and serves as a basis for development of this scientific publication" [2]. All this, of course, opens great prospects before the "Computer Optics", including in the international scientific and information space.

\section{References}

1. Soifer VA. Quo vadis. Computer Optics, 2014; 38(4): 589.

2. Sokolov VO. 25 years of the journal "Computer Optics". Proceedings of SSC RAS, 2012; 14(6): 7-12 [in Russian].

3. Kazanskiy NL, Kharitonov SI, Khonina SN, Volotovskiy SG, Strelkov YuS. Simulation of hyperspectrometer on spectral linear variable filters. Computer Optics, 2014; 38(2): 256270 [in Russian].

4. Kuznetsov AV, Myasnikov VV. A comparison of algorithms for supervised classification using hyperspectral data. Computer Optics, 2014; 38(3): 494-502 [in Russian].

5. Kazanskiy NL, Kharitonov SI, Karsakov AV, Khonina SN. Modeling action of a hyperspectrometer based on the Offner scheme within geometric optics. Computer Optics, 2014; 38(2): 271-280 [in Russian].

6. Zimichev EA, Kazanskiy NL, Serafimovich PG. Spectral-spatial classification with kmeans ++ particional clustering. Computer Optics, 2014; 38(2): 281-286 [in Russian].

7. Denisova AYu, Myasnikov VV. Anomaly detection for hyperspectral imaginary. Computer Optics, 2014; 38(2): 287-296 [in Russian].

8. Alimenkov IV. Hamiltonian approach in nonlinear fiber optics. Computer Optics, 2015; 39(1): 83-86. DOI: 10.18287/0134-2452-2015-39-1-83-86 [in Russian].

9. Vorotnikova DG, Golovashkin DL. Long vectors algorithms for solving grid equations of explicit difference schemes. Computer Optics, 2015; 39(1): 87-99. DOI: 10.18287/01342452-2015-39-1-87-93 [in Russian].

10. Lyubutin PS. Development of optical flow computation algorithms for strain measurement of solids. Computer Optics, 2015; 39(1): 94-100. DOI: 10.18287/0134-2452-2015-39-194-100.

11. Kozlova ES, Kotlyar VV, Degtyarev SA. Simulation of resonance focusing of a picosecond pulse by a dielectric microcylinder. Computer Optics, 2015; 39(1): 45-51. DOI: 10.18287/0134-2452-2015-39-1-45-51 [in Russian].

12. Agafonov AN, Volodkin BO, Kaveev AK, Kachalov DG, Knyazev BA, Kropotov GI, Tukmakov KN, Pavelyev VS, Tsypishka DI, Choporova YuYu. Binary doe with elongated focal depth to focus terahertz free electron laser radiation (novofel). Computer Optics, 2015; 39(1): 58-63. DOI: 10.18287/0134-2452-2015-39-1-58-63 [in Russian]. 
13. Kazanskiy NL, Kharitonov SI, Khonina SN. Simulation of a hyperspectrometer based on linear spectral filters using vector bessel beams. Computer Optics, 2014; 38(4): 770-776 [in Russian].

14. Doskolovich LL, Bezus EA, Bykov DA. On the compensation of the diffraction orders overlap effect in the Offner spectrometera. Computer Optics, 2014; 38(4): 777-781[in Russian].

15. Results and prospects of Project 5-100 discussed at a seminar in UrFU. Source: $<$ http://5top100.com/news/28454/>.

16. Proceedings of the 4th International Scientific and Practical Conference "Scientific Periodicals of the International Level - 2015: current trends in the world of editing, publication and evaluation of scientific publications." Source: $<$ http://conf.neicon.ru/materials/15-Domestic0515/Materials-0515.pdf > [in Russian].

17. Kolomiets EI. Analysis of activity of the scientific journal Computer Optics. CEUR Workshop Proceedings, 2015; 1490: 138-150. DOI: 10.18287/1613-0073-2015-1490-138150 .

18. Stafeev SS, Nalimov AG, Kotlyar MV, O'Faolain L. A four-zone reflective azimuthal micropolarizer. Computer Optics, 2015; 39(5): 709-715. DOI: 10.18287/0134-2452-201539-5-709-715 [in Russian].

19. Boori MS, Kuznetsov AV, Choudhary KK, Kupriyanov AV. Satellite image analysis to evaluate the urban growth and land use changes in the city of Samara from 1975 to 2015. Computer Optics, 2015; 39(5): 818-822. DOI: 10.18287/0134-2452-2015-39-5-818-822 [in Russian].

20. Thanh DNH, Dvoenko SD. Image noise removal based on total variation. Computer Optics, 2015; 39(4): 564-571. DOI: 10.18287/0134-2452-2015-39-4-564-571.

21. Zvekov AA, Kalenskii AV, Nikitin AP, Aduev BP. Radiance distribution simulation in a transparent medium with Fresnel boundaries containing aluminum nanoparticles. Computer Optics, 2014; 38(4): 749-756.

22. Fursov VA, Bibikov SA, Bajda OA. Thematic classification of hyperspectral images using conjugacy indicator. Computer Optics, 2014; 38(1): 154-158 [in Russian].

23. Kazanskiy NL, Khonina SN, Skidanov PV, Morozov AA, Kharitonov SI, Volotovskiy SG. Formation of images using multilevel diffractive lens. Computer Optics, 2014; 38(3): 425434 [in Russian]. 